\title{
Physical development and mental health in South African perinatally HIV-positive adolescents on antiretroviral therapy and their caregivers with and without household food insecurity
}

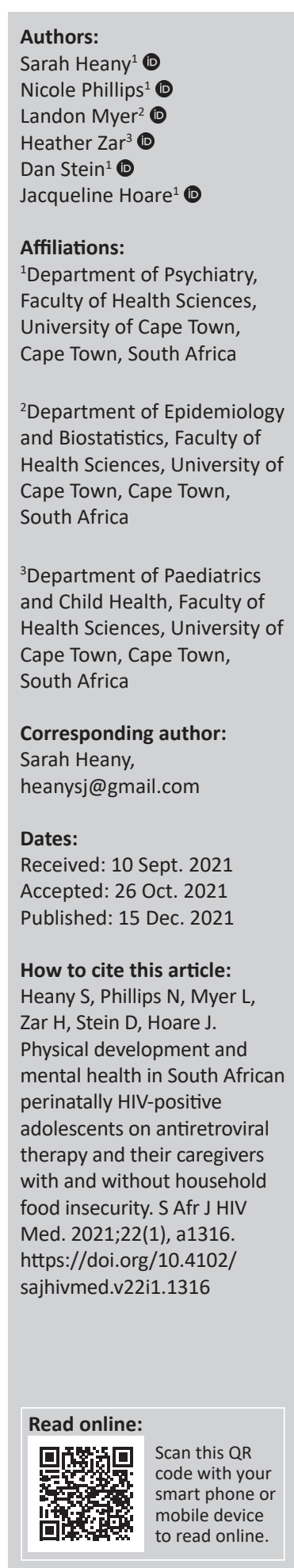

\begin{abstract}
Background: Perinatally acquired HIV-infected (PHIV+) adolescents have shown impairments in neurocognitive function and mental health problems compared with their peers. The contribution of food insecurity to such impairments has not been explored.
\end{abstract}

Objectives: The aim of this report has been to explore the contribution of food insecurity to neurocognitive impairment and mental health problems in adolescents with perinatallyacquired HIV infection.

Method: A total of 248 PHIV+ adolescents and healthy controls aged between 9 and 12 years completed a neuropsychological battery, the Childhood Behaviour Checklist (CBCL) and the Becks Youth Inventory. Head circumference, body mass index (BMI), height for age (HAZ), Tanner pubertal staging, albumin, haemoglobin, CD4 and viral loads were also measured. Participants' caregivers were interviewed about their mental health and household food security. T-tests were used to assess for differences in food secure and food insecure households.

Results: Caregivers of PHIV+ adolescents reported higher levels of depressive symptoms and household food insecurity. Increased food insecurity was associated with more behavioural problems in adolescents, as well as lower haemoglobin and albumin levels, faster processing speed and increased Tanner staging in boys. Body mass index and HAZ were not affected by food insecurity.

Conclusion: These findings suggest that household food insecurity is associated with some altered behavioural, physical and physiological outcomes, which could complicate and compound the existing difficulties in PHIV+ households.

Keywords: HIV; caregiver depression; behavioural problems; hunger risk; food security; poverty.

\section{Introduction}

Adolescents with perinatally acquired HIV infection (PHIV+) have worse outcomes in general cognitive development and mental health compared with age-matched HIV-negative peers, $1,2,3,4,5$ with the socioeconomic status as a potential cofounder. ${ }^{6}$ These include a poorer function in cognitive domains, such as working memory, executive function and processing speed, ${ }^{2}$ and a higher prevalence of attention deficit hyperactivity disorder (ADHD) symptoms, depressive symptoms, anger, disruptive behaviour, self-concept or functional competence. ${ }^{4}$ Both physiological and socio-environmental conditions have been implicated in these associations, in youth and adolescents, specifically with increased stress or mental ill health in their caregivers. ${ }^{7}$ A South African study ${ }^{8}$ found that depression amongst caregivers was strongly associated with problematic adolescent behaviour, more so than the HIV status.

Cognitive and behavioural problems in youth are also aggravated in situations of poverty. ${ }^{9}$ Food insecurity specifically has been associated with increased cognitive and behavioural problems in children and adolescents. Both externalising and internalising subscales of the Childhood Behaviour Checklist (CBCL), ${ }^{10,11}$ as well as behaviour reports from teachers, ${ }^{12}$ have been associated with food insecurity. In addition, food insecurity has been associated with lower antiretroviral therapy (ART) adherence in rural Ugandan HIV-affected households. ${ }^{13}$ South African PHIV+ Copyright: @ 2021. The Authors. Licensee: AOSIS. This work is licensed under the Creative Commons Attribution License. 
adolescents also often experience high rates of orphanhood and living with extended family, often in unstable living environments. ${ }^{14}$

Studies examining problematic or disruptive behaviour in PHIV+ adolescents are sparse. ${ }^{15}$ In addition, the impact of food insecurity on measures of cognition, affect, and behaviour may play a moderating role in the developing mental health of adolescents, but such findings have not been reported in the existing literature. In this study, we investigated the effects of household food insecurity on mental health conditions of adolescents and caregivers.

\section{Methods \\ Participants and setting}

This is a cross-sectional analysis of enrolment data from a neuropsychiatric sub-study of the Cape Town Adolescent Antiretroviral Cohort (CTAAC), a study of PHIV+ adolescents on ART in a large city in South Africa. The neuropsychiatric sub-study recruited PHIV+ adolescents from ART services across the municipality. These adolescents were eligible to participate if they were aged 9-12 years, were on ART for $>6$ months and knew their HIV status. HIV-negative healthy controls (HCs) were frequency matched with PHIV+ participants on age, sex and ethnicity. All adolescents screened for the HC cohort underwent rapid HIV testing to confirm their negative status. The exclusion criteria for both groups were as follows: (1) an uncontrolled medical condition, such as diabetes mellitus, epilepsy and tuberculosis (TB) requiring hospital admission; (2) an identified central nervous system (CNS) condition, including meningitis(TBorbacterial), cerebrovascular accident, lymphoma, history of head injury with loss of consciousness greater than $5 \mathrm{~min}$ or any radiological evidence of skull fracture, history of perinatal complications, including hypoxic ischaemic encephalopathy or neonatal jaundice requiring exchange transfusion, or neurodevelopmental disorder not attributed to HIV. The primary caregiver of each participant provided written informed consent prior to participation, and each participant provided his or her assent for participation. All data were obtained from $204 \mathrm{PHIV}+$ and 44 HC participants between 2013 and 2015.

\section{Measures}

Adolescents had a clinical examination, including Tanner staging and anthropometry. A blood sample for measuring albumin, CD4 and viral load (VL) was taken. Weight was measured in kilograms on a Scales 2000 calibrated digital scale to the nearest $0.1 \mathrm{~kg}$. The standing height was measured in centimetres using a stadiometer with a moveable headboard to the nearest $0.1 \mathrm{~cm} .{ }^{16}$ Body mass index (BMI) was calculated from the measured height and weight as weight/height ${ }^{\wedge} 2$ $\left(\mathrm{kg} / \mathrm{m}^{\wedge} 2\right)$. In order to assess for stunting, height for age $\mathrm{Z}$ scores (HAZ) were calculated separately for girls and boys using the $2007 \mathrm{WHO}$ growth reference for school-aged children and adolescents (available at http:/ / www.who.int/ growthref/tools/en/). Weight for age $\mathrm{Z}$ scores are not recommended for children over the age of 10 years.
Adolescents completed the following measures: Beck Youth Inventories ${ }^{17}$ was used to assess depression, anxiety, anger, disruptive behaviour and self-concept. Each participant was assessed using a battery of standardised neuropsychological tests, including measures of processing speed and working memory, as used in paediatric assessment and research in South Africa. ${ }^{2}$ Antiretroviral therapy adherence was recorded using a self-report questionnaire. Tests were administered in the adolescents' home language.

Caregivers completed the following measures regarding the adolescents' behaviour: The $\mathrm{CBCL}^{18}$ to assess their adolescents' behavioural and emotional problems and psychopathology using four subscales: total problems, total competence, internalising behaviour and externalising behaviour. Conners Parent Rating Scale ${ }^{19}$ was used to assess ADHD symptoms. Adolescent ART adherence was also reported on by the caregivers.

Caregivers completed the following measures regarding their own experiences: Caregiver depression was measured using the Center for Epidemiological Studies-Depression (CES-D) ${ }^{20}$ The Community Childhood Identification Project Hunger Index (CCHIP) food security scale, as used in the South African National Health and Nutrition Examination $2012,{ }^{21}$ was used to assess household food security. Scores were obtained via an eight-point self-reported questionnaire as completed by the legal guardian of the adolescent (see Appendix 1). A score of 0 indicates food secure and a score of $>1$ indicates food insecure.

Center for Epidemiological Studies-Depression, CBCL, household poverty, cognitive performance, and Tanner staging (indicating pubertal development), were assessed at baseline. Food security data were collected at a 6-month follow-up. Albumin and haemoglobin $(\mathrm{Hb})$ levels were recorded 12 months after the baseline.

\section{Statistics}

Differences in mental health, cognition and behaviour in the adolescents, as well as depression of the caregiver, were assessed between the food security groups (food secure and food insecure). These tests were carried out in the combined sample (PHIV+ and HC together) and in the PHIV+ group alone. The tests were not carried out in the HC group alone as there were not enough HC participants in the food insecure category to facilitate comparative tests. Mean measures of albumin, $\mathrm{Hb}$ and physical development were assessed between the food secure and food insecure groups. Differences in the above measures were also assessed between the PHIV+ and HC groups. The ART adherence scores were tested for differences based on food security levels. The different measures of disruptive behaviour (Becks Disruptive Behaviour [BDB] and CBCL subscales) were tested for correlations. Statistical tests were conducted using Statistical Package for the Social Sciences (SPSS) for Windows, version 26 (IBM Corp., Armonk, New York, United States). For all tests of interval data, $t$-test was used. For tests of 
categorical data (Tanner staging, home language and repeated grades), chi-square tests were used. Levene's test for equality of variances was assessed for each $t$-test to determine whether a Mann-Whitney test was required. In post hoc and sensitivity testing, some behavioural and affective measures were assessed for correlations using Pearson's correlation coefficients.

\section{Ethical considerations}

This study was approved by the University of Cape Town's Faculty of Health Sciences Human Research Ethics Committee (HREC REF 051/2013) and is in accordance with the Declaration of Helsinki. All data were obtained from $204 \mathrm{PHIV}+$ and $44 \mathrm{HC}$ CTAAC participants between 2013 and 2015.

\section{Results}

\section{Overall results in the full sample}

The mean annual income was just under $\$ 350.00$, on average, for both PHIV+ and HC households, classified as extreme poverty $\left(<\$ 1.90\right.$ per day) by the World Bank..$^{22}$ The median age of the sample (including PHIV+ and HC) was 10.8 years. Tanner staging was higher in girls than boys. A total of 225 adolescent caregivers provided food security scores, with 50 indicating food insecurity. The average age of ART onset in the PHIV+ group was 3.4 years, with a standard deviation of 2.53. In the PHIV+ group, the median CD4 count was 903 cells $/ \mathrm{mm}^{3}$, and the mean was 957 cells $/ \mathrm{mm}^{3}$. About $17 \%$ of the PHIV+ group had detectable VL levels of over 50 copies/mL. The findings as well as differences between the PHIV and HC groups have been listed (Table 1).

\section{Differences between perinatally acquired HIV infection and healthy controls groups}

Levels of poverty were well-matched between the PHIV+ and HC groups. Despite matched poverty levels, $26 \%$ of PHIV+ households experience food insecurity, whilst only $5 \%$ of HC households reported food insecurity. The number of repeated grades differed between the groups, with $59 \%$ of the PHIV+ group and $42 \%$ of the HC group having repeated a grade. Albumin levels were lower in the PHIV+ group. Body weight, height, HAZ, BMI and female Tanner scores were all lower in the PHIV+ group. The median HAZ score in the PHIV+ group was -2 and in the HC group was -1.9. Caregiver depression and food insecurity were higher in the PHIV+ group. In the PHIV+ group, 203 caregivers provided CES-D scores, 94 of whom are considered at risk for depression (a score of $\geq 16$ ). ${ }^{23}$ In the HC group, 44 parents completed the CES-D, 13 of whom had a score of $\geq 16$.

\section{Affect and cognitive scores by food insecurity (Table 2)}

In the combined sample (PHIV+ and $\mathrm{HC}$ group), $\mathrm{Hb}$ and albumin levels were lower in the food insecure group. Problem behaviour, as measured by CBCL Total Problems (CBCL-TP), was higher in the food insecure group $(t=2.05(220), P=0.042)$. Cognitive domains and BMI did not differ according to food insecurity in the combined sample.
TABLE 1: Baseline demographic and clinical characteristics of the cohort, comparing perinatally acquired HIV infection and healthy controls groups.

\begin{tabular}{|c|c|c|c|c|c|c|c|}
\hline \multirow[t]{2}{*}{ Variable } & \multicolumn{3}{|c|}{$\begin{array}{c}\text { PHIV+ } \\
(N=203)\end{array}$} & \multicolumn{3}{|c|}{$\begin{array}{c}\mathrm{HC} \\
(N=43)\end{array}$} & \multirow[t]{2}{*}{$P$} \\
\hline & Mean & s.d. & $\%$ & Mean & s.d. & $\%$ & \\
\hline Age (years) & 10.79 & 0.9 & - & 10.72 & 1.0 & - & 0.65 \\
\hline Gender & - & - & - & - & - & - & 0.73 \\
\hline Male & 94 & - & - & 19 & - & - & - \\
\hline Female & 104 & - & - & 24 & - & - & - \\
\hline Height, $(\mathrm{cm})$ & 133.9 & 7.7 & - & 138.5 & 8.8 & - & $<0.01^{*}$ \\
\hline HAZ scores & -1.24 & 1.0 & - & -0.35 & 1.0 & - & $<0.01^{*}$ \\
\hline Weight, (kg) & 30.8 & 7.3 & - & 36.7 & 11.4 & - & $<0.01^{*}$ \\
\hline BMI & 17.1 & 3.0 & - & 18.8 & 3.8 & - & $<0.01 *$ \\
\hline Head circumference, $(\mathrm{cm})$ & 52.9 & 2.1 & - & 53.6 & 3.1 & - & 0.09 \\
\hline Tanner stage (boys), $\%$ at & - & - & - & - & - & - & 0.54 \\
\hline
\end{tabular}

(boys), $\%$ at

each stage

State 1

Stage 2

Stage 3

Tanner stage (girls), $\%$ at

each stage

State $1 \quad$ - $\quad-\quad 52 \quad-\quad 5 \quad-\quad 21$

Stage 2

Stage 3

Stage 4

$\begin{array}{llllllll} & 12.5 & 1.1 & - & 12.8 & 1.1 & - & 0.18\end{array}$

$\begin{array}{lllllllll}\text { Albumin, } \mathrm{g} / \mathrm{L} & 42.9 & 3.5 & - & 45.1 & 2.9 & - & <0.01 *\end{array}$

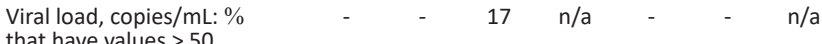

CD4 count, cells $/ \mathrm{mm}^{3} \quad 957484 \quad-\quad \mathrm{n} / \mathrm{a} \quad-\quad-\quad$ n/a

Home language: $\%$ isiXhosa
speakers

$\begin{array}{llllllll}\text { Household income bracket } \dagger & 2.9 & 0.7 & - & 2.7 & 0.5 & - & 0.21\end{array}$

$\begin{array}{llllllll}\text { Food insecurity } & 1.1 & 2.3 & - & 0.2 & 1.3 & - & 0.02 *\end{array}$

$\begin{array}{lllllllll}\text { Current school grade } & 4.2 & 1.4 & - & 4.4 & 1.1 & - & 0.24\end{array}$

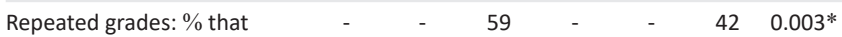

have repeated

$\begin{array}{llllllll}\text { Caregiver depression } & 16.0 & 12.4 & - & 11.3 & 10.8 & - & 0.02 *\end{array}$

(CES-D)

Note: $P$-values are provided from $t$-tests carried out for interval data and chi-square tests for nominal data. Values are reported as mean (s.d.) unless indicated otherwise.

PHIV+, perinatally acquired HIV infection; HC, healthy controls; BMI, body mass index;

CES-D, Center for Epidemiological Studies-Depression; HAZ, height for age.

*, Statistical significance with a threshold of $P<0.05$.

$\dagger$, Household annual income brackets: 1 : $\$ 0.00 ; 2$ : $\$ 1.00-\$ 350.00 ; 3: \$ 351.00-\$ 1500.00$;

4: $>\$ 1500.00$.

The BDB measure of disruptive behaviour almost differed $(P=0.078)$, whilst depression, anxiety and anger did not differ. A test correlating $\mathrm{BDB}$ scores with $\mathrm{CBCL}$ scores showed that BDB was correlated with CBCL TP $(r=0.23, P<$ 0.001), but not with the other CBCL subscales (externalising behaviour, internalising behaviour and total competence). Tanner stage in boys was slightly higher in the food insecure group, although boys' ages were very closely matched (10.7 years in the food secure group and 10.8 years in the food insecure group). When the subscales of the CBCL were compared between the food secure and food insecure groups, only CBCL-TP was significantly different.

\section{Affect and cognitive scores by food insecurity amongst perinatally acquired HIV-infected adolescents}

When the PHIV+ group was investigated on its own, problem behaviour as measured by CBCL-TP was no longer significantly different between the food security group 
TABLE 2: Baseline demographic and clinical characteristics of the cohort, comparing food insecure and food secure.

\begin{tabular}{|c|c|c|c|c|c|c|c|c|c|c|c|c|c|c|}
\hline \multirow[t]{3}{*}{ Variable } & \multicolumn{6}{|c|}{ Combined group (PHIV+ and $\mathrm{HC}$ ) } & \multirow[t]{3}{*}{$p$} & \multicolumn{6}{|c|}{ PHIV+ only } & \multirow[t]{3}{*}{$p$} \\
\hline & \multicolumn{3}{|c|}{$\begin{array}{c}\text { Food insecure } \\
(N=50)\end{array}$} & \multicolumn{3}{|c|}{$\begin{array}{c}\text { Food secure } \\
(N=174)\end{array}$} & & \multicolumn{3}{|c|}{$\begin{array}{c}\text { PHIV+ Food insecure } \\
(N=48) \\
\end{array}$} & \multicolumn{3}{|c|}{$\begin{array}{c}\text { PHIV+ Food secure } \\
(N=135)\end{array}$} & \\
\hline & Mean & s.d. & $\%$ & Mean & s.d. & $\%$ & & Mean & s.d. & $\%$ & Mean & s.d. & $\%$ & \\
\hline Age (years) & 10.8 & 0.9 & - & 10.8 & 0.9 & - & 0.54 & 10.8 & 0.9 & - & 10.8 & 0.8 & - & 0.95 \\
\hline Gender & - & - & - & - & - & - & 0.94 & - & - & - & - & - & - & 0.84 \\
\hline Male & 24 & - & - & 83 & - & - & - & 23 & - & - & 67 & - & - & - \\
\hline Female & 26 & - & - & 92 & - & - & - & 25 & - & - & 68 & - & - & - \\
\hline Height (cm) & 134.8 & 7.9 & - & 134.5 & 7.9 & - & 0.84 & 134.7 & 8.1 & - & 133.4 & 7.3 & - & 0.32 \\
\hline HAZ scores & -1.22 & 1.0 & - & -1.08 & 1.1 & - & 0.40 & -1.24 & 1.0 & - & -1.28 & 1.0 & - & 0.84 \\
\hline Weight (kg) & 31.0 & 5.5 & - & 32.1 & 9.1 & - & 0.44 & 30.8 & 5.5 & - & 30.8 & 7.8 & - & 0.95 \\
\hline BMI & 16.9 & 2.0 & - & 17.5 & 3.6 & - & 0.30 & 16.9 & 1.9 & - & 17.2 & 3.5 & - & 0.51 \\
\hline Head circumference & 52.8 & 2.3 & - & 53.1 & 2.4 & - & 0.40 & 52.8 & 2.4 & - & 53.0 & 2.1 & - & 0.52 \\
\hline Tanner stage (boys) $\%$ at each stage & - & - & & - & - & - & $0.04 *$ & - & - & - & - & - & - & 0.15 \\
\hline Stage 1 & - & - & 74 & - & - & 93 & - & - & - & 77 & - & - & 94 & - \\
\hline Stage 2 & - & - & 26 & - & - & 6 & - & - & - & 23 & - & - & 5 & - \\
\hline Tanner stage (girls) $\%$ at each stage & - & - & & - & - & - & 0.07 & - & - & - & - & - & - & 0.26 \\
\hline Stage 1 & - & - & 62 & - & - & 40 & - & - & - & 60 & - & - & 48 & - \\
\hline Stage 2 & - & - & 30 & - & - & 47 & - & - & - & 32 & - & - & 39 & - \\
\hline Stage 3 & - & - & 8 & - & - & 10 & - & - & - & 8 & - & - & 10 & - \\
\hline Stage 4 & - & - & & - & - & 3 & - & - & - & - & - & - & 3 & - \\
\hline $\mathrm{HB}$ g/dL & 12.3 & 1.3 & - & 12.7 & 1.1 & - & $0.05^{*}$ & 12.4 & 1.3 & - & 12.6 & 1.1 & - & 0.14 \\
\hline Albumin $\mathrm{g} / \mathrm{L}$ & 42.4 & 3.7 & - & 43.7 & 3.3 & - & $0.02 *$ & 42.5 & 3.7 & - & 43.2 & 3.3 & - & 0.22 \\
\hline Viral load copies/mL: \% > 50 PHIV+ only & - & - & 17 & - & - & $15 \%$ & 0.32 & - & - & 17 & - & - & 15 & 0.32 \\
\hline CD4 count cells $/ \mathrm{mm}^{3} \mathrm{PHIV}+$ only & 960 & 445 & - & 931 & 446 & - & 0.70 & 960 & 445 & - & 931 & 446 & - & 0.70 \\
\hline ART adherence (self-reported; PHIV+ only) & 14.54 & 2.3 & - & 14.65 & 2.0 & - & 0.76 & 14.54 & 2.3 & - & 14.65 & 2.0 & - & 0.76 \\
\hline ART adherence (parent reported; PHIV+ only) & 14.29 & 2.0 & - & 14.46 & 2.0 & - & 0.64 & 14.29 & 2.0 & - & 14.46 & 2.0 & - & 0.64 \\
\hline Household income bracket $\dagger$ & 2.8 & 0.6 & - & 2.9 & 0.7 & - & 0.41 & 2.8 & 0.6 & - & 2.9 & 0.7 & - & 0.21 \\
\hline Food insecurity & 4.1 & 2.8 & - & 0 & 0 & - & $<0.01 *$ & 4.1 & 2.8 & - & 0 & 0 & - & $<0.01^{*}$ \\
\hline Current school grade & 3.2 & 1.2 & - & 3.2 & 1.2 & - & 0.90 & 3.2 & 1.2 & - & 3.2 & 1.1 & - & 0.78 \\
\hline No & 20 & - & - & 78 & - & - & - & - & - & - & 54 & - & - & - \\
\hline Caregiver depression (CES-D) & 17.1 & 11.7 & - & 14.5 & 12.2 & - & 0.18 & 17.6 & 11.6 & - & 15.5 & 12.4 & - & 0.32 \\
\hline Child Behavior Checklist - Total problems (CBCL-TB) & 58.0 & 11.4 & - & 53.9 & 11.0 & - & $0.02 *$ & 58.0 & 11.6 & - & 54.5 & 11.5 & - & 0.07 \\
\hline Child behavior checklist - Total competence & 38.7 & 8.0 & - & 38.1 & 8.0 & - & 0.62 & 38.6 & 7.8 & - & 37.3 & 7.9 & - & 0.33 \\
\hline Child behavior checklist - Internalising problems & 58.6 & 12.1 & - & 56.7 & 10.7 & - & 0.29 & 58.8 & 12.3 & - & 57.0 & 11.1 & - & 0.36 \\
\hline Child behavior checklist - Externalising problems & 55.2 & 10.9 & - & 52.3 & 10.8 & - & 0.10 & 55.0 & 11.0 & - & 52.9 & 11.0 & - & 0.26 \\
\hline ADHD (Conners) & 17.0 & 14.0 & - & 14.4 & 14.6 & - & 0.79 & 16.8 & 13.9 & - & 15.6 & 15.2 & - & 0.39 \\
\hline Beck's self-Concept & 45.9 & 10.1 & - & 46.6 & 8.6 & - & 0.65 & 45.3 & 9.8 & - & 46 & 8.9 & - & 0.67 \\
\hline Beck's anxiety & 54.7 & 13.4 & - & 53.1 & 13.1 & - & 0.46 & 55.0 & 13.6 & - & 52.9 & 13.7 & - & 0.36 \\
\hline Beck's depression & 48.1 & 11.9 & - & 45.4 & 10.3 & - & 0.12 & 48.6 & 11.9 & - & 46.4 & 10.6 & - & 0.22 \\
\hline Beck's anger & 46.8 & 13.7 & - & 43.8 & 11.2 & - & 0.11 & 47.4 & 13.7 & - & 44.0 & 11.6 & - & 0.11 \\
\hline Beck's disruptive behaviour (BDB) & 46.1 & 8.9 & - & 43.5 & 9.4 & - & 0.08 & 46.5 & 8.9 & - & 44.2 & 9.6 & - & 0.16 \\
\hline Processing speed (Z score) & -0.42 & 0.7 & - & -0.48 & 0.7 & - & 0.60 & -0.40 & 0.7 & & -0.63 & 0.7 & - & $0.04 *$ \\
\hline
\end{tabular}

Note: $P$-values are provided from $t$-tests carried out in the case of interval data, and chi-square tests in the case of nominal data. Values are reported as mean (s.d.) unless indicated otherwise. PHIV+, perinatally acquired HIV infection; HC, healthy controls; BMI, body mass index; CES-D, Center for Epidemiological Studies-Depression; HAZ, height for age; Hb, haemoglobin; ART, antiretroviral therapy; ADHD, attention deficit hyperactivity disorder; s.d., standard deviation.

*, Statistical significance with a threshold of $P<0.05$.

$\dagger$, Household annual income brackets: 1 : $\$ 0.00 ; 2$ : \$1.00-\$350.00; 3: \$351.00-\$1500.00; 4: > \$1500.00.

( $t=1.82(180), P=0.07)$. It should be mentioned that this change in $P$-value from 0.04 to 0.07 (along with a change in $t$-score from 2.05 to 1.82) may be because of the smaller $n$ in this test of this subsample. Amongst the cognitive domains, only processing speed differed amongst the food security groups, with food insecurity being associated with faster processing speed. We noted that processing speed was not different between the food secure and food insecure groups when the PHIV+ and HC were combined $(t=-0.53, P=0.60)$, only within the PHIV+ sample, as shown in Table 2 . There was no difference in reported ART adherence between the food secure and food insecure groups.

\section{Discussion}

This study of the CTAAC adolescent cohort found that food insecurity was associated with problem behaviour, as measured by CBCL-TP. In addition, processing speed was faster in PHIV+ adolescents who experience household food insecurity. We also found that food insecurity was not associated with working memory, CBCL Total Competence or Conners ADHD scale. Becks inventory scores of depression, anxiety, anger and disruptive behaviour were also not significantly associated with food security, although the data trended towards the food insecure groups having 
higher scores in each of these inventory domains. In the whole sample (PHIV+ and HC combined), lower $\mathrm{Hb}$ and albumin levels were associated with food insecurity. Perinatally acquired HIV infection households were more likely to have food insecurity and caregiver depression. Lower height, weight, BMI and albumin levels were also related to PHIV status.

Problem behaviour differed according to level of household food insecurity. Becks Disruptive Behaviour and CBCL-TP also correlated strongly. It is, therefore, possible that both being PHIV+ and having food insecurity in the home may compound adolescent problem behaviour. A longitudinal study conducted in the United States found that whilst there are higher rates of problem behaviour in HIV+ children, demographic factors such as level of parental education may be a stronger cause of problem behaviour than HIV diagnosis. ${ }^{24}$ A study on a South African cohort of PHIV+ children and adolescents also found that problem behaviour was not directly linked to HIV status, but instead was more associated with caregiver depression. ${ }^{8}$ This study adds to these findings by including household food insecurity and shows that it may have a modulating effect on problem behaviour in adolescents. Overall, the literature points to a complex interaction of social and demographic factors that influence problem behaviour in $\mathrm{PHIV}+$ and healthy adolescents. Interestingly, a study from Atlanta, Georgia, on HIV+ children and adolescents $(97 \%$ perinatally infected) and controls showed that whilst psychological maladjustment was high in the HIV+ group, it was even higher in the control group, specifically with regard to internalising behaviour. ${ }^{25}$ Problem behaviour, particularly problematic conduct, has previously been associated with decreased ART adherence in PHIV+ children and adolescents in the United States. ${ }^{26}$ Food insecurity has also been associated with lower ART adherence in rural Ugandan HIV+ households. ${ }^{13}$ Whilst this may have severe implications for the ongoing health and HIV+ population, our PHIV+ sample did not show any differences in reported adherence in relation to food insecurity.

In our cohort, height, weight, BMI, HAZ and Tanner staging in girls were all lower in the PHIV+ group, indicating stunted growth; however, these growth biomarkers were not related to food insecurity. A study in Tanzanian adolescents has previously associated food insecurity with undernutrition and lower BMI, although mental health was not measured. ${ }^{27}$ Alternately, in the North American populations, food insecurity has been associated with an increased risk of obesity and metabolic syndrome in both adults and adolescents. ${ }^{28,29,30,31}$ This inconsistency in published results may be because of different lifestyle norms and factors of poverty in each studied population. A review focussing on Western countries found that food insecurity had deleterious consequences of emotional, cognitive and behavioural outputs in children and adolescents. $^{32}$ A UK-based study found that cognitive differences in food insecurity groups could be explained by poverty levels, and behavioural development could be explained by environmental and parental treatment in the home; emotional problems were, however, ascribed to food insecurity alone. ${ }^{33}$ This study tries to piece these different factors together; however, more longitudinal data are required.

There are some limitations to this study. One is the crosssectional design; however, follow-up analyses with this cohort are underway. The food security data, household income, mental health, and problem behaviour measures in this study were all self-reported by parents or legal guardians, which leaves some room for error, given that answers rely on recall. Responses to measures, such as the food security questionnaire, are vulnerable to biased reporting from participants. This bias can depend on the participants' comfort and familiarity with the data collection team, and may be influenced by inhibition or alternately a tendency towards expected responses when facing many questions about experienced difficulties. Another limitation here is the small size of the HC group; however, the group was well matched. Different measures of food insecurity are used in research studies across the world because of different living conditions and norms; however, this currently seems necessary, given differing socio-cultural contexts. In order to clarify the associations between problem behaviour, HIV status, poverty indicators, nutrition, development and mental states, the effects of specific family and household dynamics of affected children and adolescents should be studied further, especially using objective food security measures and with research designs that facilitate understanding of causal pathways.

In conclusion, PHIV+ adolescents suffer delays in physical development, including BMI, HAZ, pubertal development and lower circulating albumin levels. Household food insecurity further affects albumin and $\mathrm{Hb}$ levels and increases the likelihood of behavioural problems in PHIV+ adolescents.

\section{Acknowledgements Competing interests}

The authors declare that they have no financial or personal relationships that may have inappropriately influenced them in writing this article.

\section{Authors' contributions}

S.J.H. carried out the statistical analyses and wrote the first draft of the manuscript. N.P. coordinated and supervised data collection and entry, and critically reviewed the manuscript. J.H. was the principal investigator of this study, and critically reviewed and approved the manuscript before submission. H.J.Z. was the principal investigator on Cape Town Adolescent Antiretroviral Cohort (CTAAC), and critically reviewed the manuscript. D.J.S. and L.M. assisted in study conceptualisation, advised on statistical analysis and critically reviewed the manuscript. All authors read and approved the final manuscript.

\section{Funding information}

J.H. has received support from Medical Research Council (MRC) of South Africa. H.J.Z. and D.J.S. are supported by 
the NRF and the MRC of South Africa. S.J.H has received support from the Oppenheimer Memorial Trust. This research work was supported by NICHD under Grant number R01HD074051.

\section{Data availability}

The data that support the findings of this study are available from the corresponding author, S.J.H., upon reasonable request.

\section{Disclaimer}

The views expressed in this article are those of the authors and not an official position of the institution or the funders.

\section{References}

1. Hoare J, Phillips N, Joska JA, et al. Applying the HIV-associated neurocognitive disorder diagnostic criteria to HIV-infected youth. Neurology. 2016;87(1):86-93. https://doi.org/10.1212/WNL.0000000000002669

2. Phillips NJ, Hoare J, Stein DJ, Myer L, Zar HJ, Thomas KG. HIV-associated cognitive disorders in perinatally infected children and adolescents: A novel composite cognitive domains score. AIDS Care. 2018;30(Suppl 1):8-16. https://doi.org/10.10 80/09540121.2018.1466982

3. Nozyce ML, Lee SS, Wiznia A, et al. A behavioral and cognitive profile of clinically stable HIV-infected children. Pediatrics. 2006;117:763-770. https://doi. org/10.1542/peds.2005-0451

4. Hoare J, Phillips N, Brittain K, Myer L, Zar HJ, Stein DJ. Mental health and functional competence in the Cape Town adolescent antiretroviral cohort. JAIDS J Acquir Immune Defic Syndr. 2019;81(4):e109-e116. https://doi.org/10.1097/ QAl.0000000000002068

5. Phillips N, Amos T, Kuo C, et al. HIV-associated cognitive impairment in perinatally infected children: A meta-analysis. Pediatrics. 2016;138:e20160893. https://doi. org/10.1542/peds.2016-0893

6. Boyede GO, Lesi FE, Ezeaka VC, Umeh CS. Impact of sociodemographic factors on cognitive function in school-aged HIV-infected Nigerian children. HIV/AIDS 2013;5:145. https://doi.org/10.2147/HIV.S43260

7. Baker BL, McIntyre LL, Blacher J, Crnic K, Edelbrock C, Low C. Pre-school children with and without developmental delay: Behaviour problems and parenting stress over time. J Intellect Disabil Res. 2003;47(4-5):217-230. https://doi.org/10.1046/ j.1365-2788.2003.00484.x

8. Louw KA, Ipser J, Phillips $\mathrm{N}$, Hoare J. Correlates of emotional and behavioura problems in children with perinatally acquired HIV in Cape Town, South Africa. AIDS Care. 2016;28(7):842-850. https://doi.org/10.1080/09540121.2016.1140892

9. Pachter LM, Auinger $P$, Palmer R, Weitzman M. Do parenting and the home environment, maternal depression, neighborhood, and chronic poverty affect child behavioral problems differently in different racial-ethnic groups? Pediatrics. 2006;117(4):1329-1338. https://doi.org/10.1542/peds.2005-1784

10. Whitaker RC, Phillips SM, Orzol SM.. Food insecurity and the risks of depression and anxiety in mothers and behavior problems in their preschool-aged children. Pediatrics. 2006;118(3):e859-e868. https://doi.org/10.1542/peds.2006-0239

11. Slopen N, Fitzmaurice G, Williams DR, Gilman SE. Poverty, food insecurity, and the behavior for childhood internalizing and externalizing disorders. J Am Acad Child Adolesc Psychiatry. 2010;49(5):444-452. https://doi.org/10.1097/00004583201005000-00005

12. Howard LL. Does food insecurity at home affect non-cognitive performance at school? A longitudinal analysis of elementary student classroom behavior. Econ Educ Rev. 2011;30(1):157-176. https://doi.org/10.1016/j.econedurev.2010.08.003
13. Weiser SD, Palar K, Frongillo EA, et al. Longitudinal assessment of associations between food insecurity, antiretroviral adherence and HIV treatment outcomes in rural Uganda. AIDS. 2014;28(1):115. https://doi.org/10.1097/01.aids.0000433238.93986.35

14. Kuo C, Operario, D. Health of adults caring for orphaned children in an HIVendemic community in South Africa. AIDS Care. 2011;23(9):1128-1135. https:// doi.org/10.1080/09540121.2011.554527

15. Brittain K, Myer L, Phillips N, et al. Behavioural health risks during early adolescence among perinatally HIV-infected South African adolescents and sameage, HIV-uninfected peers. AIDS Care. 2019;31(1):131-140. https://doi.org/10.10 80/09540121.2018.1533233

16. Kuhle S, Maguire B, Ata N, Hamilton D. Percentile curves for anthropometric measures for Canadian children and youth. PLoS One. 2015;10(7):e0132891. https://doi.org/10.1371/journal.pone.0132891

17. Bose-Deakins JE, Floyd RG. A review of the Beck Youth Inventories of emotional and social impairment. J Sch Psychol. 2004;42(4):333-340. https://doi org/10.1016/j.jsp.2004.06.002

18. Ivanova MY, Achenbach TM, Dumenci L, et al. Testing the 8-syndrome structure of the child behavior checklist in 30 societies. J Clin Child Adolesc Psychology. 2007;36(3):405-417. https://doi.org/10.1080/15374410701444363

19. Conners CK, Sitarenios G, Parker JD, Epstein JN. The revised Conners' parent rating scale (CPRS-R): Factor structure, reliability, and criterion validity. J Abnorm Child Psychol. 1998;26(4):257-268. https://doi.org/10.1023/A:1022606501530

20. Irwin M Artin KH, Oxman MN. Screening for depression in the older adult: Criterion validity of the 10-item Center for Epidemiological Studies Depression Scale (CES-D). Arch Intern Med. 1999;159(15):1701-1704. https://doi org/10.1001/archinte.159.15.1701

21. Shisana O, Labadarios D, Rehle T, et al. The South African national health and nutrition examination survey, 2012: SANHANES-1: The health and nutritional status of the nation. Cape Town: HSRC Press; 2014.

22. The World Bank. Decline of global extreme poverty continues but slowed [homepage on the Internet]. 2018 [cited 2021 Dec 7]. Available from: https:// www.worldbank.org/en/news/press-release/2018/09/19/decline-of-globalextreme-poverty-continues-but-has-slowed-world-bank

23. Lewinsohn PM, Seeley JR, Roberts RE, Allen NB. Center for epidemiological studies-depression scale (CES-D) as a screening instrument for depression amon community-residing older adults. Psychol Aging. 1997;12:277-287. https://doi. org/10.1037/0882-7974.12.2.277

24. Mellins CA, Smith R, O'Driscoll $P$, et al. High rates of behavioral problems in perinatally HIV-infected children are not linked to HIV disease. Pediatrics. 2003;111:384-393. https://doi.org/10.1542/peds.111.2.384

25. Bachanas PJ, Kullgren KA, Schwartz KS, et al. Predictors of psychological adjustment in school-age children infected with HIV. J Pediatr Psychol. 2001;26:343-352. https://doi.org/10.1093/jpepsy/26.6.343

26. Malee K, Williams $P$, Montepiedra G, et al. Medication adherence in children and adolescents with HIV infection: Associations with behavioral impairment. AIDS Patient Care STDS. 2011;25:191-200. https://doi.org/10.1089/apc.2010.0181

27. Cordeiro LS, Lamstein S, Mahmud Z, Levinson FJ. Adolescent malnutrition in developing countries: A close look at the problem and at two national experiences. Vol. 31. SCN News, 2006; p. 6-13.

28. Casey PH, Simpson PM, Gossett JM, et al. The association of child and household food insecurity with childhood overweight status. Pediatrics. 2006;118(5):e1406-e1413. https://doi.org/10.1542/peds.2006-0097

29. Parker L. Food insecurity and obesity: A dual challenge for low-income families Zero to Three. 2007;28(1):24-30.

30. Larson NI, Story MT. Food insecurity and weight status among US children and families: A review of the literature. Am J Prev Med. 2011;40(2):166-173. https:// doi.org/10.1016/j.amepre.2010.10.028

31. Rose D, Bodor JN. Household food insecurity and overweight status in young school children: Results from the early childhood longitudinal study. Pediatrics. 2006;117(2):464-473. https://doi.org/10.1542/peds.2005-0582

32. Shankar P, Chung R, Frank DA. Association of food insecurity with children's behavioral, emotional, and academic outcomes: A systematic review. J Dev Behav Pediatr. 2017;38(2):135-150. https://doi.org/10.1097/DBP.0000000000000383

33. Belsky DW, Moffitt TE, Arseneault L, Melchior M, Caspi, A. Context and sequelae of food insecurity in children's development. Am J Epidemiol. 2010;172(7): 809-818. https://doi.org/10.1093/aje/kwq201 


\section{Appendix}

APPENDIX 1: The community childhood identification project hunger index food security scale.

Please answer 'Yes' or 'No' to each of the following questions:

2. Do you ever rely on a limited number of foods to feed your children because you are running out of money to buy food for a meal?

3. Do you ever cut the size of meals or skip any because there is not enough food in the house?

4. Do you ever eat less than you should because there is not enough money for food?

$\square$ Yes

$\square$ Yes 